\title{
Impact of depression and social support on nonadherence to antipsychotic drugs in persons with schizophrenia in Thailand
}

This article was published in the following Dove Press journal:

Patient Preference and Adherence

13 September 2010

Number of times this article has been viewed

\author{
Sirijit Suttajit \\ Sutrak Pilakanta \\ Department of Psychiatry, Faculty \\ of Medicine, Chiang Mai University, \\ Chiang Mai, Thailand
}

Background: Little is known about the effect of social support on nonadherence in persons with schizophrenia, especially in developing Asian countries where social support is considered to be imperative. Additionally, the role of depression as a mediator in the association between social support deficits and nonadherence has not been evaluated.

Methods: This was a cross-sectional study conducted in 75 participants at a university hospital in Thailand. Logistic regression was used to determine whether depression and a deficit in social support were associated with nonadherence, and whether depression mediated this association. Results: There were strong relationships between nonadherence and major depressive episodes (odds ratio [OR] 9.5, confidence interval [CI] 2.3-38.9), living alone (OR 21.8, CI 3.5-143.0), and dissatisfaction with support from family (OR 10.0, CI 1.9-53.1). The OR of the association between social support deficits and nonadherence decreased by nearly one half after adjusting for depression.

Discussion: Depression and social support deficits were significantly associated with nonadherence in persons with schizophrenia. Depression is important in mediating the association between social support deficits and nonadherence. Enhancing social support, as well as early detection and effective intervention for depression should be emphasized in interventions to improve adherence in persons with schizophrenia.

Keywords: nonadherence, schizophrenia, depression, social support, antipsychotic drugs

\section{Introduction}

Antipsychotic drugs have been proved to be effective in treating persons with schizophrenia, yet nonadherence with the drugs ranges from $20 \%$ to $89 \%$. ${ }^{1,2}$ Nonadherence often leads to negative consequences, including relapse, rehospitalization, poor functional outcomes, and suicide. ${ }^{3,4}$

Several factors have been found to be associated with nonadherence, including illness-related factors (eg, severity of symptoms, insight, duration of illness), treatmentrelated factors (eg, type of antipsychotic, side effects), and patient-related factors (eg, stigma, level of education, attitude toward illness, substance abuse). ${ }^{5}$ Depression has also been recognized as one of the strongest predictors of nonadherence in persons with schizophrenia ${ }^{6}$ and, in turn, nonadherence with antipsychotic drugs more than triples the suicide risk in these persons. ${ }^{7}$

Depression is common in the course of schizophrenia. The lifetime prevalence of major depressive episodes in schizophrenia has been estimated to be around $60 \%$, and the point prevalence ranges widely from $10 \%$ to $83 \%$, depending on the clinical setting, assessment, duration of study, and characteristics of the study population. ${ }^{8,9}$
Correspondence: Sirijit Suttajit Department of Psychiatry, Faculty of Medicine, Chiang Mai University, Chiang Mai, Thailand 50200

Tel $+668244 \mid 9559$

Fax+6653945426

Email ssuttaji@mail.med.cmu.ac.th 
Bartels and Drake categorized depressive symptoms in schizophrenia into three subtypes, ie, depressive symptoms secondary to general medical or substance-related factors, depressive symptoms occurring with acute psychotic episode, and depressive symptoms occurring without acute psychotic symptoms (such as prodromal symptoms, post-psychotic symptoms, and negative symptoms). ${ }^{10}$

Hudson et al found that lack of social support is one of the most common barriers to adherence reported by persons with schizophrenia, ${ }^{13}$ although some studies reported insignificant associations between social support and nonadherence. ${ }^{14-16}$ Because the lack of social support from family and neighbors is associated with suicide in persons with schizophrenia, ${ }^{11}$ depression may mediate the association between social support deficit and nonadherence. Social support deficit may lead to depression via decreased self-esteem, coping skills, and resilience, as well as an increase in experience of stigma. ${ }^{11,12}$ In Thai culture, which is the focus of this paper, persons with schizophrenia generally live with their family members. Therefore, social support is considered critical for Thai persons with schizophrenia because they receive financial as well as emotional support from the family. However, little is known about the effect of social support on nonadherence in persons with schizophrenia because limited aspects of social support have been studied. Moreover, social support may vary from one culture to another, which may limit comparability of findings across cultures, and modification to measurement strategies might be required. ${ }^{17}$ In addition, the role of depression in the association between social support deficits and nonadherence in persons with schizophrenia has not been evaluated.

The purposes of this study were to assess the independent association of depression and social support deficit with nonadherence to antipsychotic drugs, and to evaluate the mediating effect of depression on the association between social support deficit and nonadherence to antipsychotic drugs. We hypothesized that depression and social support deficit were independently associated with nonadherence, and that the effect of social support deficit on nonadherence was mediated by depression.

\section{Methods}

This was a cross-sectional study conducted at an outpatient clinic of a university hospital in Chiang Mai, Thailand. We estimate the sample size required at $90 \%$ power and $5 \%$ significance to be 72 participants. Therefore, after approval by the Ethics Committee, Faculty of Medicine, Chiang Mai University, 75 participants were recruited from December 2009 to February 2010. The inclusion criteria were Thai-speaking, aged 18 years or over, diagnosis of schizophrenia according to Diagnostic and Statistical Manual of Mental Disorders, 4th Edition, Text Revision (DSM-IV-TR), ${ }^{18}$ and receiving oral antipsychotic drugs. The exclusion criterion was receiving depot antipsychotic within the past month.

We used a clinician-rated visual analog scale (0\%-100\%) with an $80 \%$ cut-off point ${ }^{4}$ for evaluating nonadherence in the past month. Major depressive episodes were diagnosed by psychiatrists according to DSM-IV-TR.${ }^{18}$ Social support was derived from the scale of six social support deficits (SSDs) which had been found to be highly salient to depression in a previous study. ${ }^{19}$ These social support deficits were defined as living alone, seeing a relative less often than once a week, lack of reciprocity with neighbours, lack of reciprocity between extended family members, relationship difficulty with one or more relatives, and dissatisfaction with support from family.

The association of nonadherence against each baseline characteristic was analyzed using Chi-square tests and logistic regression $(P<0.05)$. Odds ratios (ORs) and $95 \%$ confidence intervals (CIs) were calculated using logistic regression for the association between depression, social support deficits, and nonadherence. The association between social support and nonadherence were reported before and after adjustment for depression to identify the mediating effect of depression. The association between depression and nonadherence were reported before and after adjustment for age, gender, marital status, and income which were chosen a priori as they might associate with depression or nonadherence and, therefore, confound the association. ${ }^{19}$

\section{Results}

Of the 75 participants included in the study, 26 (34.7\%) were male, 23 (30.7\%) were married, 41 (54.7\%) had completed at least high school, and $36(48.0 \%)$ were working. The mean age was $46.8 \pm 14.1$ years in the adherence group and $42.2 \pm 10.6$ years in the nonadherence group. The baseline characteristics significantly associated with nonadherence were type of antipsychotic drugs, side effects, and satisfaction with treatment (Table 1).

The prevalence of nonadherence in the current study was $16.0 \%$. Sixteen percent of the participants had major depressive episodes. Those with major depressive episodes were 9.5 times more likely to be nonadherent to antipsychotic drugs than those without depression before adjustment. The odds association was still significant after adjustment for age, gender, marital status, and income (Table 2). 
Table I Baseline characteristics and nonadherence

\begin{tabular}{|c|c|c|c|c|}
\hline Baseline characteristic & $\begin{array}{l}\text { Total } \\
(n=75) \\
n(\%)\end{array}$ & $\begin{array}{l}\text { Adherent } \\
(n=63) \\
n(\%)\end{array}$ & $\begin{array}{l}\text { Nonadherent } \\
(\mathrm{n}=\mathrm{I} 2) \\
\mathrm{n}(\%)\end{array}$ & $P$ value \\
\hline \multicolumn{5}{|l|}{ Gender } \\
\hline Male & $26(34.7)$ & $20(31.7)$ & $6(50.0)$ & 0.321 \\
\hline Female & $49(35.3)$ & $43(68.3)$ & $6(50.0)$ & \\
\hline \multicolumn{5}{|l|}{ Age (years) } \\
\hline$\leq 40$ & $28(37.3)$ & $22(34.9)$ & $6(50.0)$ & 0.346 \\
\hline$>40$ & $47(62.7)$ & $4 I(65.1)$ & $6(50.0)$ & \\
\hline \multicolumn{5}{|l|}{ Marital status } \\
\hline Married & $23(30.7)$ & $20(31.7)$ & $3(25.0)$ & 0.745 \\
\hline Single, widowed, or divorced & $52(69.3)$ & $43(68.3)$ & $9(75.0)$ & \\
\hline \multicolumn{5}{|l|}{ Income (Baht/month) } \\
\hline No income & $33(44.0)$ & $28(44.4)$ & $5(4 \mid .7)$ & 0.232 \\
\hline$\leq 10,000$ & $24(32.0)$ & $18(28.6)$ & $6(50.0)$ & \\
\hline$>10,000$ & $18(24.0)$ & $17(27.0)$ & I (8.3) & \\
\hline \multicolumn{5}{|l|}{ Work status } \\
\hline Working & $39(52.0)$ & $34(54.0)$ & $5(4 \mid .7)$ & 0.434 \\
\hline Not working or being a housewife & $36(48.0)$ & $29(46.0)$ & $7(58.3)$ & \\
\hline \multicolumn{5}{|l|}{ Duration of illness } \\
\hline $0-10$ years & $37(49.3)$ & $29(46.0)$ & $8(66.7)$ & 0.190 \\
\hline$>10$ years & $28(50.7)$ & $34(54.0)$ & $4(33.3)$ & \\
\hline \multicolumn{5}{|l|}{ Antipsychotic } \\
\hline Typical & $38(50.7)$ & $28(44.4)$ & $10(83.3)$ & 0.014 \\
\hline Atypical & $37(49.3)$ & $35(55.6)$ & $2(16.7)$ & \\
\hline \multicolumn{5}{|l|}{ Number of side effect } \\
\hline $0-1$ & $31(4 \mid .3)$ & $30(47.6)$ & I (8.3) & 0.012 \\
\hline$>1$ & $44(58.7)$ & $33(52.4)$ & II (9I.7) & \\
\hline \multicolumn{5}{|l|}{ Satisfaction with treatment } \\
\hline Most satisfied & $34(45.3)$ & $31(49.2)$ & $3(25.0)$ & 0.007 \\
\hline Very satisfied & $29(38.7)$ & $25(39.7)$ & $4(33.0)$ & \\
\hline Medium satisfied & $9(12)$ & $6(9.5)$ & $3(25.0)$ & \\
\hline Less satisfied & $2(2.7)$ & $0(0)$ & $2(16.7)$ & \\
\hline Not satisfied & $\mathrm{I}(\mathrm{I} .3)$ & $0(0)$ & I (8.3) & \\
\hline
\end{tabular}

Of all persons with schizophrenia, 9.3\% lived alone, $13.3 \%$ saw a relative less often than once a week, $10.7 \%$ reported lack of reciprocity with neighbors, $9.3 \%$ felt that members in the family did not care about each other, $12 \%$ had experienced upset in a relationship with a relative, and $9.3 \%$ were not satisfied with the support they received from their relatives. Two out of the six social support deficits were significantly associated with nonadherence, including living alone and dissatisfaction with support from family. However, after adjustment for depression, the association between dissatisfaction with support from family and nonadherence became nonsignificant. Forty-three percent of the participants had at least one social support deficit. Those with at least one social support deficit were 5.2 times more likely to be nonadherent to antipsychotic drugs than those without a social support deficit. The odds of nonadherence dropped to 3.1 and were not significant after being adjusted for depression (Table 3).

\section{Discussion}

Our study shows that nonadherence to antipsychotic drugs in schizophrenia is a complex and multifactorial phenomenon.

Table 2 The association between depression and nonadherence

\begin{tabular}{|c|c|c|c|c|}
\hline Depression & $\begin{array}{l}n \\
(n=75)\end{array}$ & $\begin{array}{l}\% \\
\text { Nonadherence }\end{array}$ & $\begin{array}{l}\text { Unadjusted } \\
\text { OR ( } 95 \% \mathrm{CI})\end{array}$ & $\begin{array}{l}\text { Adjusted } \\
\text { OR }^{\mathrm{a}}(95 \% \mathrm{CI}) \\
\end{array}$ \\
\hline Noncase & 62 & 9.5 & I. 0 & I. 0 \\
\hline Case & 12 & 50 & $9.5(2.3-38.9)$ & $8.3(1.9-35.8)$ \\
\hline
\end{tabular}

Note: aAjusted for age, sex, marital status, and income. Abbreviations: $\mathrm{OR}$, odds ratio; $\mathrm{Cl}$, confidence interval. 
Table 3 The association between social support deficits and nonadherence

\begin{tabular}{|c|c|c|c|c|}
\hline Six social support deficits & $\begin{array}{l}n \\
(n=75)\end{array}$ & $\begin{array}{l}\% \\
\text { Nonadherence }\end{array}$ & $\begin{array}{l}\text { Unadjusted } \\
\text { OR ( } 95 \% \mathrm{Cl})\end{array}$ & $\begin{array}{l}\text { Adjusted } \\
\text { OR }^{\mathrm{a}}(95 \% \mathrm{Cl})\end{array}$ \\
\hline Living alone & 7 & 71.4 & $21.8(3.5-134.0)$ & I3.4 (I.9-94.3) \\
\hline Seeing a relative less often than once a week & 10 & 50.0 & $6.1(0.8-48.4)$ & $3.5(0.3-37.4)$ \\
\hline Lack of reciprocity with neighbors & 8 & 25.0 & $1.9(0.3-10.7)$ & $1.6(0.2-11.0)$ \\
\hline Lack of reciprocity between extended family members & 7 & 28.6 & $2.3(0.4-13.6)$ & I.I (0.5-8.9) \\
\hline Difficulty in relationship with one or more relatives & 9 & $\mathrm{II} . \mathrm{I}$ & $0.6(0.1-5.5)$ & $0.4(0.04-4.8)$ \\
\hline Dissatisfaction with support from family & 7 & 57.1 & $10.0(1.9-53.1)$ & $5.3(0.8-34.0)$ \\
\hline \multicolumn{5}{|l|}{ Number of social support deficits } \\
\hline No social support deficit & 43 & 7.0 & 1.0 & 1.0 \\
\hline At least one social support deficit & 32 & 28.1 & $5.2(|.3-2| .2)$ & $3.1(0.7-14.1)$ \\
\hline
\end{tabular}

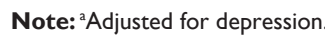

Abbreviations: OR, odds ratio; $\mathrm{Cl}$, confidence interval.

The findings confirm the relationship between depression, social support deficit, as well as other factors, including type of antipsychotic drugs, side effects, and satisfaction with nonadherence in persons with schizophrenia.

Depression may lead to nonadherence via impairing cognitive functioning, which affect a person's ability to follow through with treatment. ${ }^{20,21}$ Moreover, because positive beliefs in the benefits of treatment are important for adherence, pessimistic thoughts about the illness and loss of faith in treatment which are commonly found in depressed persons ${ }^{11}$ may lead to nonadherence. Evidence of depression affecting nonadherence has been found in other illnesses, including infectious disease, diabetes, heart disease, and osteoporosis. ${ }^{22-25}$ Because persons with schizophrenia already suffer from negative symptoms, the impact of depression on reducing motivation, which associates with nonadherence, ${ }^{26}$ might be stronger than in other patient groups. ${ }^{15}$

Of the six social support deficits, living alone was the strongest factor associated with nonadherence, with the OR as high as over 20; however, the association between living alone and nonadherence decreased by nearly a half after being adjusted for depression. The impact of depression was similar in the association between the number of social support deficits and nonadherence. Taken together, our findings suggest that social support deficits are risk factors for nonadherence in schizophrenia, and that the associations may be partially mediated by depression, thereby adding to the limited knowledge about the relationship between social support, depression, and nonadherence in schizophrenia.

Apart from being mediated by depression, social support deficit may lead to nonadherence directly via decreased coping skills, motivation, and resilience, as well as increased experience of stigma and emotional conflict. ${ }^{12,27}$ Persons who live alone may lack medication supervision and have difficulty accessing medical care. ${ }^{1}$ In addition, it was found that lack of support from family might hinder persons with schizophrenia in achieving rehabilitation. ${ }^{28}$

Our findings are in line with the review by Lacro et al which reported that age, gender, marital status, and duration of illness were not associated with nonadherence. ${ }^{1}$ About half of Thai persons with schizophrenia in this study received typical antipsychotic drugs. This percentage is higher than in Western countries which mostly use atypical ones. ${ }^{29,30}$ We found that adherence with atypical antipsychotic drugs was significantly better than with typical ones. This parallels previous studies which found that there was an overall trend toward greater adherence among persons receiving atypical antipsychotic drugs. ${ }^{1,31}$ Our findings are also consistent with those of a previous study showing that individuals who switched from a typical to an atypical antipsychotic drug were more adherent than those who had their typical antipsychotic drug maintained. ${ }^{32}$

Typical antipsychotic drugs are more likely to produce extrapyramidal side effects and akathisia, which may directly lead to nonadherence. It is also suggested that typical antipsychotic drugs are depressogenic by blocking dopamine 2 receptors $^{33}$ and may lead to nonadherence via depression. Fewer side effects, as well as the effectiveness of atypical antipsychotic drugs in managing psychotic symptoms, might make it more likely that persons will continue their treatment. Thus, the choice of antipsychotic drug affects adherence to those drugs.

This study, in parallel with previous studies, ${ }^{34,35}$ shows that side effects impact antipsychotic adherence. A study by Yamada et al found that the most common reason for nonadherence in Japanese persons with schizophrenia was "distressed by side effects". ${ }^{36}$ In contrast, studies of persons with first-episode schizophrenia reported negative findings. ${ }^{6,37}$ Perkins et al suggested that stage of illness and experience with antipsychotic side effects may have an impact on the contribution of side effects to nonadherence. ${ }^{6}$ 
Although this study leads to a better understanding of the association between nonadherence, social support, depression, and other variables, certain limitations exist. Firstly, the direction of causality among variables cannot be determined due to the cross-sectional study design. It is possible that there might be a vicious cycle whereby depression and social support deficit cause nonadherence which, in turn, worsen depression and social support deficit. In addition, nonadherence may change over time, although some studies have found it to be quite stable. ${ }^{38}$

Secondly, nonadherence was assessed based on psychiatrist judgment only, so it may have been underestimated. Moreover, psychiatrists' judgment of adherence may have been biased by the clinical state of the patients. ${ }^{39}$

Thirdly, it should be borne in mind that the social support deficit scale was developed to assess social support deficit in older adults, and therefore, measurement error might have occurred through the adaptation of the social support deficit scale to a different sample. Moreover, use of a clinician-rated visual analog scale, although easily assessed and commonly used to assess adherence, may have limited validity and underestimated nonadherence. This limitation might explain the relatively low prevalence of nonadherence found in this study and might be the reason why we did not find associations between some of the social support deficit subscale items and nonadherence. However, this would not explain our positive findings.

Fourthly, the small sample size might limit our positive findings and might explain the low frequency of comorbid depression found in this study, although the result is in line with the findings reported in a previous survey in Thailand..$^{40}$ In addition, research in the hospital setting might lead to selection bias because individuals who are nonadherent are more likely to be lost to follow-up during the treatment process, and the particular sample characteristics from a university hospital in Thailand might reduce generalizability to other persons with schizophrenia in different settings. Future research in a community setting, conducted in a larger number of persons with schizophrenia or other psychotic disorders, is necessary for a better understanding of nonadherence.

In conclusion, this study shows that depression and social support deficits were significantly associated with nonadherence in persons with schizophrenia. Depression is important in mediating the association between social support and nonadherence in persons with schizophrenia. Other baseline characteristics found to be associated with nonadherence were receiving typical antipsychotic drugs, having more than one side effect, and being less satisfied with treatment.
Enhancing social support, which is a modifiable factor, should be emphasized in intervention to improve adherence in persons with schizophrenia. Early detection and effective intervention for depression, as well as concern about drug side effects and patient satisfaction might be useful in dealing with nonadherence in persons with schizophrenia.

\section{Disclosure}

The authors report no conflicts of interest in this work.

\section{References}

1. Lacro JP, Dunn LB, Dolder CR, Leckband SG, Jeste DV. Prevalence of and risk factors for medication nonadherence in persons with schizophrenia: A comprehensive review of recent literature. J Clin Psychiatry. 2002;63(10):892-909.

2. Lieberman JA, Stroup TS, McEvoy JP, et al. Effectiveness of antipsychotic drugs in patients with chronic schizophrenia. $N$ Engl J Med. 2005;353(12):1209-1223.

3. Viguera AC, Baldessarini RJ, Hegarty JD, van Kammen DP, Tohen M. Clinical risk following abrupt and gradual withdrawal of maintenance neuroleptic treatment. Arch Gen Psychiatry. 1997;54(1):49-55.

4. Donohoe G, Owens N, O'Donnell C, et al. Predictors of compliance with neuroleptic medication among inpersons with schizophrenia: A discriminant function analysis. Eur Psychiatry. 2001;16(5):293-298.

5. Velligan DI, Weiden PJ, Sajatovic M, et al. The expert consensus guideline series: Adherence problems in persons with serious and persistent mental illness. J Clin Psychiatry. 2009; 70 Suppl 4:1-46; quiz 7-8.

6. Perkins DO, Gu H, Weiden PJ, McEvoy JP, Hamer RM, Lieberman JA. Predictors of treatment discontinuation and medication nonadherence in persons recovering from a first episode of schizophrenia, schizophreniform disorder, or schizoaffective disorder: A randomized, double-blind, flexible-dose, multicenter study. J Clin Psychiatry. 2008; 69(1):106-113.

7. Herings RM, Erkens JA. Increased suicide attempt rate among persons interrupting use of atypical antipsychotics. Pharmacoepidemiol Drug Saf. 2003;12(5):423-424.

8. Buckley PF, Miller BJ, Lehrer DS, Castle DJ. Psychiatric comorbidities and schizophrenia. Schizophr Bull. 2009;35(2):383-402.

9. Martin RL, Cloninger CR, Guze SB, Clayton PJ. Frequency and differential diagnosis of depressive syndromes in schizophrenia. J Clin Psychiatry. 1985;46(11 Pt 2):9-13.

10. Bartels SJ, Drake RE. Depressive symptoms in schizophrenia: Comprehensive differential diagnosis. Compr Psychiatry. 1988;29(5): 467-483.

11. Roy A, Pompili M. Management of schizophrenia with suicide risk. Psychiatr Clin North Am. 2009;32(4):863-883.

12. Hardy SE, Concato J, Gill TM. Resilience of community-dwelling older persons. J Am Geriatr Soc. 2004;52(2):257-262.

13. Hudson TJ, Owen RR, Thrush CR, et al. A pilot study of barriers to medication adherence in schizophrenia. J Clin Psychiatry. 2004;65(2): 211-216.

14. Compton MT, Rudisch BE, Weiss PS, West JC, Kaslow NJ. Predictors of psychiatrist-reported treatment-compliance problems among persons in routine U.S. psychiatric care. Psychiatry Res. 2005;137(1-2): 29-36.

15. Elbogen EB, Swanson JW, Swartz MS, van Dorn R. Medication nonadherence and substance abuse in psychotic disorders: Impact of depressive symptoms and social stability. J Nerv Ment Dis. 2005; 193(10):673-679.

16. Sapra M, Vahia IV, Reyes PN, Ramirez P, Cohen CI. Subjective reasons for adherence to psychotropic medication and associated factors among older adults with schizophrenia. Schizophr Res. 2008;106(2-3): $348-355$. 
17. Broadhead J, Abas M, Sakutukwa GK, Chigwanda M, Garura E. Social support and life events as risk factors for depression amongst women in an urban setting in Zimbabwe. Soc Psychiatry Psychiatr Epidemiol. 2001;36(3):115-122.

18. American Psychiatric Association. Diagnostic and Statistical Manual of Mental Disorders. 4th ed. (Text Revision) Washington, DC: American Psychiatric Association; 2000.

19. Suttajit S, Punpuing S, Jirapramukpitak T, et al. Impairment, disability, social support and depression among older parents in rural Thailand. Psychol Med. 2010;8:1-11.

20. DiMatteo MR, Lepper HS, Croghan TW. Depression is a risk factor for noncompliance with medical treatment: Meta-analysis of the effects of anxiety and depression on patient adherence. Arch Intern Med. 2000;160(14):2101-2107.

21. Weinberger MI, Mateo C, Sirey JA. Perceived barriers to mental health care and goal setting among depressed, community-dwelling older adults. Patient Prefer Adherence. 2009;3:145-149.

22. Bane C, Hughes CM, McElnay JC. The impact of depressive symptoms and psychosocial factors on medication adherence in cardiovascular disease. Patient Educ Couns. 2006;60(2):187-193.

23. Mehta SH, Thomas DL, Sulkowski MS, Safaein M, Vlahov D, Strathdee SA. A framework for understanding factors that affect access and utilization of treatment for hepatitis $\mathrm{C}$ virus infection among $\mathrm{HCV}$ mono-infected and HIV/HCV-co-infected injection drug users. AIDS. 2005;19 Suppl 3:S179-S189.

24. Rossini M, Bianchi G, Di Munno O, et al. Determinants of adherence to osteoporosis treatment in clinical practice. Osteoporos Int. 2006; 17(6):914-921.

25. Sobel RM, Markov D. The impact of anxiety and mood disorders on physical disease: The worried not-so-well. Curr Psychiatry Rep. 2005;7(3):206-212.

26. Williams GC, Rodin GC, Ryan RM, Grolnick WS, Deci EL. Autonomous regulation and long-term medication adherence in adult outpersons. Health Psychol. 1998;17(3):269-276.

27. DiMatteo MR. Social support and patient adherence to medical treatment: A meta-analysis. Health Psychol. 2004;23(2):207-218.

28. Aquila R, Weiden PJ, Emanuel M. Compliance and the rehabilitation alliance. J Clin Psychiatry. 1999;60 Suppl 19:23-27; discussion 8-9.
29. Kuno E, Rothbard AB. Racial disparities in antipsychotic prescription patterns for persons with schizophrenia. Am J Psychiatry. 2002;159(4): 567-572.

30. Lenderts S, Kalali AH, Buckley P. Generic penetration in the retail atypical antipsychotic market. Psychiatry (Edgmont). 2010;7(3): 9-10.

31. Ascher-Svanum H, Zhu B, Faries DE, Lacro JP, Dolder CR, Peng X. Adherence and persistence to typical and atypical antipsychotics in the naturalistic treatment of persons with schizophrenia. Patient Prefer Adherence. 2008;2:67-77.

32. Janssen B, Gaebel W, Haerter M, Komaharadi F, Lindel B, Weinmann S. Evaluation of factors influencing medication compliance in inpatient treatment of psychotic disorders. Psychopharmacology (Berl). 2006; 187(2):229-236.

33. Bressan RA, Costa DC, Jones HM, Ell PJ, Pilowsky LS. Typical antipsychotic drugs $-\mathrm{D}_{2}$ receptor occupancy and depressive symptoms in schizophrenia. Schizophr Res. 2002;56(1-2):31-36.

34. Lambert M, Conus P, Eide P, et al. Impact of present and past antipsychotic side effects on attitude toward typical antipsychotic treatment and adherence. Eur Psychiatry. 2004;19(7):415-422.

35. Perkins DO. Predictors of noncompliance in persons with schizophrenia. J Clin Psychiatry. 2002;63(12):1121-1128.

36. Yamada K, Watanabe K, Nemoto N, et al. Prediction of medication noncompliance in outpersons with schizophrenia: 2-year follow-up study. Psychiatry Res. 2006;141(1):61-69.

37. Perkins DO, Johnson JL, Hamer RM, et al. Predictors of antipsychotic medication adherence in persons recovering from a first psychotic episode. Schizophr Res. 2006;83(1):53-63.

38. Ascher-Svanum H, Faries DE, Zhu B, Ernst FR, Swartz MS, Swanson JW. Medication adherence and long-term functional outcomes in the treatment of schizophrenia in usual care. J Clin Psychiatry. 2006; 67(3):453-460.

39. Velligan DI, Wang M, Diamond P, et al. Relationships among subjective and objective measures of adherence to oral antipsychotic medications. Psychiatr Serv. 2007;58(9):1187-1192.

40. Siriwanarangsun P, Kongsuk T, Arunpongpaisan S, Kittirattanapaiboon P, Charatsingha A. Prevalence of mental disorders in Thailand: A national survey 2003. Journal of Mental Health of Thailand. 2004;12(3):178-188.
Patient Preference and Adherence

\section{Publish your work in this journal}

Patient Preference and Adherence is an international, peer-reviewed, open access journal focusing on the growing importance of patient preference and adherence throughout the therapeutic continuum. Patient satisfaction, acceptability, quality of life, compliance, persistence and their role in developing new therapeutic modalities and compounds to

\section{Dovepress}

optimize clinical outcomes for existing disease states are major areas of interest. This journal has been accepted for indexing on PubMed Central. The manuscript management system is completely online and includes a very quick and fair peer-review system. Visit http://www.dovepress.com/ testimonials.php to read real quotes from published authors. 